the policy of closing psychiatric beds and hospitals. The forensic implications of community care, TAPS reports a $40 \%$ increase in the number of acute obviously of great concern to the public and media, patients thought to need admission, but only a $12 \%$ should be revealed by further exploration of this rich increase in the number who were actually admitted. source of data.

\title{
The Association of Pakistani Psychiatrists
}

This Organisation (APP) has been set up to provide a forum for the exchange of information and ideas and to bring together the views and experiences of colleagues working in psychiatry in the UK.

One of the immediate aims of the organisation is to set up a scientific journal for circulation in the UK and in Pakistan. Contributions will be invited from practitioners in both countries, with an emphasis on clinical and epidemiological aspects of psychiatry.

The professional and educational remit of the APP will be to examine the possibility of providing final year student elective placements, participation in the
Overseas Doctors' Training Scheme, and helping out in areas previously identified as requiring assistance, such as preparation of curriculum vitae and examination techniques. We also intend to hold regular academic meetings comprising internal contributions as well as speakers invited specifically for their expertise in the subject under discussion.

The first meeting of the Executive Committee has taken place and we are now in the process of launching a membership drive. All enquiries should be sent to Dr Ahmad Mahmood, Association of Pakistani Psychiatrists, 18 Hardy Close, Hinckley, Leicestershire, LE10 IPF (Telephone 0455 250842). 